\title{
Анализ опыта развития перфоманс-контрактинга в России
}

\author{
М. К. Измайлов ${ }^{1 凶}$ \\ ${ }^{1}$ Санкт-Петербургский политехнический университет Петра Великого (СПбПУ), Высшая школа \\ управления и бизнеса, ул. Политехническая, 29, 195251, Санкт-Петербург, Российская Федерация
}

Для цитирования: Измайлов М. К. Анализ опыта развития перфоманс-контрактинга в России // Вестник Воронежского государственного университета. Серия: Экономика и управление. 2020. № 4. С. 65-73. DOI: $10.17308 /$ econ.2020.4/3194

\begin{abstract}
Предмет. На сегодняшний день в экономике Российской Федерации, и в частности на уровне промышленных предприятий, перфоманс-контракты в части модернизации и управления основными средствами практически не применяются. Весь опыт развития перфоманс-контрактинга в России напрямую связан с энергосервисными контрактами. Вместе с тем имеющийся потенциал по сокращению энергопотребления и повышению энергоэффективности даёт возможность использовать механизм перфоманс-контрактинга в России уже сегодня. Успешное развитие перфоманс-контрактинга в энергетической сфере позволяет сделать обоснованный вывод о возможности его использования и в других неэнергетических отраслях, например, в процессе управления основными средствами промышленных предприятий. В основе предлагаемого подхода к использованию перфоманс-контрактинга в управлении основными фондами промышленных предприятий лежит идея о том, что исполнитель по такому контракту берёт на себя все риски внедрения новых объектов основных средств в реальных производствах.

Цель исследования состоит в проведении анализа проблем развития перфоманс-контрактинга в России и выработке рекомендаций по его развитию.

Методология. В процессе достижения поставленных целей использовались методы научного познания: диалектический; анализа и синтеза. Исследование построено на изучении актуальной научной и периодической экономической литературы.

Результаты. Приведена краткая история становления и развития энергосервисных контрактов. Отражены основные статистические данные, характеризующие развитие рынка перфоманс-контрактинга в России на современном этапе.

Выводы. На основе проведенного исследования обоснована необходимость использования перфоманс-контрактинга в управлении основными средствами промышленных предприятий. В заключительной части статьи представлены основные причины, препятствующие массовому развитию перфоманс-контрактинга в России, а также предложены некоторые рекомендации для его развития. Обоснован вывод о необходимости продолжения работы по внедрению механизмов стимулирования промышленных предприятий в области применения перфоманс-контрактов для финансирования проектов и мероприятий по обновлению и модернизации основных фондов, а также повышению их энергоэффективности, что позволит осуществлять привлечение новых инвестиций в энергосбережение и обеспечит возврат инвестированных средств за счет экономии финансовых ресурсов.
\end{abstract}

Ключевые слова: перфоманс-контрактинг, энергосервисные контракты, энергоэффективность, перфоманс-контракт, основные средства.

\section{Введение}

В современных условиях развития экономики любого государства повышение конкурентоспособности страны и показателей уровня жизни населения невозможно без внедрения реально работающих инновационных проектов развития энергоэффективной экономики. При этом важную роль играют проекты реконструк- ции и модернизации оборудования энергоемких предприятий с использованием современных менее энергоемких агрегатов и машин, реализация которых требует существенных объемов финансирования.

Заявленная направленность России на дальнейшую интеграцию в мировое сообщество, на децентрализацию управления предопределяет

(C) Измайлов М. К., 2020

Вестник ВГУ. Серия: Экономика и управление. 2020. № 4. С. 65-73. 
потребность в формировании инновационной модели развития, установить которую позволяют структурные преобразования экономики страны и ее регионов, инновационные сдвиги в производственной и социальной сферах, сопровождаемые повышением энергоэффективности функционирования национальной экономики в различных сферах хозяйствования.

На сегодня в мире не существует универсальной модели энергоэффективного развития. Каждое государство имеет собственное видение энергоэффективного развития национальной экономики, что определяет сущность и специфику как самой модели энергоэффективности, так и механизмов, применяемых для ее обеспечения. Указанные отличия вытекают из накопленного странами опыта в сфере государственного регулирования социально-экономических процессов, из состояния и перспектив развития национальной экономики, несмотря на тенденции глобального и регионального рынков энергетических ресурсов и задачи национальной безопасности.

Становление самой прогрессивной энергоэффективной модели предусматривает структурные преобразования национальной экономики на различных уровнях управления (национальном, региональном, городском и уровне субъектов хозяйствования); нуждается в адаптации национальной экономики к рыночным ценам на энергоносители; предопределяет системное совершенствование процессов управления в энергетической сфере на всех уровнях территориально-отраслевой иерархии; требует формирования новой парадигмы государственной энергоэффективной политики, основанной на принципах эмерджентности, транспарентности, экологичности, суверенитета и социальной ответственности.

Высокая энергоемкость российской экономики, обусловленная неэффективным использованием энергоресурсов, угрожает энергетической безопасности страны, негативно влияет на окружающую среду и благосостояние граждан. Большой потенциал энергосбережения является одним из главных факторов инвестиционной привлекательности указанной сферы. Повышение уровня инвестиций в энергоэффективность позволит обеспечить не только снижение энергоемкости ВВП и удовлетворение увеличения спроса на энергоресурсы, но и позволит сократить затраты и, соответственно, повысить капиталовложения в строительство новых генерирующих мощностей. Поэтому управление инновационны- ми проектами модернизации предприятий энергоемких отраслей сегодня является чрезвычайно актуальным. Одним из распространенных в мировой практике методов инжиниринга, который применяется в системной интеграции управления энергоэффективностью, является перформанс-контрактинг, позволяющий обеспечить комплексный подход к решению задач по повышению энергоэффективности объектов на взаимовыгодных условиях как для заказчиков, так и для исполнителей энергетических услуг.

Различным аспектам функционирования рынка перфоманс-контрактинга, совершенствования механизмов государственного и регионального управления и администрирования в сфере энергоэффективности и энергосбережения посвящено большое количество профессиональных работ, в частности Ю. Г. Бозиевой, А. Б. Чапаева [2], А. В. Левицкой [8], Т. П. Лымаревой [9], А. Н. Плотникова [12], И. А. Родионовой, М. А. Мареевой [13], И. Н. Сотник, Л. А. Кулик [16] и других. Анализ возможностей энергосервисных контрактов как инструмента привлечения инвестиций в электросетевой комплекс России отражен в трудах О. Б. Хуснутдиновой [19], Л. Е. Назаровой [11], А. Е. Кирюдчевой, Д. В. Немовой [7], А. А. Бурчаковой [3]. Социально-экономические основы энергоэффективности национальной экономики разрабатывали М. А. Муртазова [1], Н. К. Грачев [4], Н. Д. Гуськова, О. В. Ульянкин [5]. Особенности современной системы функционирования рынка перфоманс-контрактинга в контексте мирового опыта описывали Т. В. Седаш, Е. К. Каменева, Д. А. Егорова [15], О. В. Ульянкин [18], А. Б. Чапаев [20] и др.

Несмотря на наличие широкого спектра разнонаправленных исследований, отдельные направления указанной сферы требуют пристального внимания со стороны ученых. Речь идет среди прочего о теоретических, методологических и прикладных аспектах управления рынком перфоманс-контрактинга в контексте формирования энергоэффективной модели развития страны. В комплексе перспективными представляются анализ состояния рынка перфоманс-контрактинга, должное инвестиционное обеспечение энергоэффективных мероприятий с учетом специфики энергопотребления в различных отраслях национальной экономики и в домохозяйствах, использования инструментов энергетического менеджмента и государственной политики в этой сфере. Актуальность и важность данных вопросов для 
национальной экономики обусловили выбор темы и определили её цель.

Цель исследования состоит в проведении анализа проблем развития перфоманс-контрактинга в России и выработке рекомендаций по его развитию.

\section{Материалы и методы исследования}

В процессе достижения поставленных целей использовались методы научного познания: диалектический; анализа и синтеза. Исследование построено на изучении актуальной научной и периодической экономической литературы.

Источниковой базой написания статьи послужили научные работы российских авторов, федеральное законодательство, а также статистические данные о развитии российского рынка энергосервиса и материалы сети Интернет.

\section{Обсуждение результатов}

На сегодняшний день в экономике Российской Федерации, и в частности на уровне промышленных предприятий, перфоманс-контракты в части модернизации и управления основными средствами практически не применяются [6]. Весь опыт развития перфоманс-контрактинга в России напрямую связан с энергосервисными контрактами. Понятие энергосервисного договора (перфоманс-контракта) впервые было введено в российское законодательство ст. 19 Федерального закона № 261-ФЗ от 23 ноября 2009 г. «Об энергосбережении и о повышении энергетической эффективности и о внесении изменений в отдельные законодательные акты Российской Федерации». Это открыло возможности для формирования новой категории участников во взаимоотношениях поставщиков и потребителей энергоресурсов - энергосервисных компаний [17].

До принятия законодательного акта энергетические перфоманс-контракты на территории Российской Федерации не приобретали существенного развития - при управлении энергосберегающими проектами промышленные компании полагались только на собственный менеджмент, используя при этом в основном заемные и лизинговые программы финансирования. В бюджетном секторе экономики законодательством о государственных закупках был регламентирован порядок приобретения объектов основных средств только по критерию самой низкой стоимости, а бюджетное законодательство не позволяло муниципальным и государственным заказчикам заключать контракты в случае, если их срок выходил за пределы трёхлетнего бюджетного цикла.

В 2010 г. Правительством РФ была принята Государственная программа «Энергосбережение и повышение энергетической эффективности», в которой законодательно было установлено определение энергосервисных контрактов (энергетических перфоманс-контрактов), а также требования к заключению таких договоров [10].

В 2014 г. при поддержке Министерства энергетики РФ и Аналитического центра при Правительстве РФ была создана специализированная организация - Ассоциация энергосервисных компаний, в состав которой вошли энергосервисные компании, компании - поставщики энергосберегающего оборудования и компании, осуществляющие инвестиции в энергосберегающие технологии. Создание Ассоциации послужило новым этапом в развитии перфоманс-контрактинга в России.

По данным Ассоциации энергосервисных компаний за 2018 г., в Единой информационной системе в сфере закупок осуществлена публикация 1047 извещений о проведении закупок на заключение энергетических перфоманс-контрактов. Всего в 2018 г. было заключено 842 энергосервисных контракта. Суммарная стоимость контрактов составила 44 137,0 млн руб. При этом наиболее многочисленной из заключенных энергетических перфоманс-контрактов является группа с ценовым диапазоном менее 100 млн руб. - 720 контрактов (табл. 1) [14].

Если ранжировать по стоимости контрактов, то доля заключенных энергетических перфо-

Т а бл ц а 1

Данные о количестве заключенных энергетических перфоманс-контрактов

по ценовым сегментам за 2018 г. (составлено автором на основе статистических данных [14])

\begin{tabular}{|c|c|c|c|}
\hline Ценовой сегмент & Количество контрактов, ед. & Стоимость контрактов, млн руб. & Удельный вес, \% \\
\hline Меньше 100 млн руб. & 720 & 5778,9 & $13,1 \%$ \\
\hline $\begin{array}{c}\text { От 100 млн до } \\
\text { 1 млрд руб. }\end{array}$ & 49 & 17556,9 & $39,8 \%$ \\
\hline Более 1 млрд руб. & 8 & 20801,2 & $47,1 \%$ \\
\hline Всего & 777 & 44137,0 & $100,0 \%$ \\
\hline
\end{tabular}


манс-контрактов с ценовым диапазоном менее 100 млн руб. достаточно низка и составляет чуть более 13 \%. Около 50 \% рынка энергетического перфоманс-контрактинга составляют контракты стоимостью более 1 млрд руб. Контракты, стоимость которых более 100 млн и менее 1 млрд руб. составили в 2018 г. 39,8 \% рынка. Стоимость контрактов изменяется от 29 тыс. руб. до 4,9 млрд руб., что говорит о большом разбросе масштабов энергосберегающих проектов, которые реализуются по модели энергетических перфоманс-контрактов [14].

Если анализировать заключенные перфоманс-контракты в отраслевом разрезе, можно увидеть, что по количеству контрактов в сегменте до 100 млн руб. доминируют объекты социальной сферы, к которой отнесены образовательные учреждения, учреждения здравоохранения (59,3 \%). Значительная часть контрактов также заключена по уличному освещению -
150 контрактов в 2018 г. (20,8 \%). Доля контрактов по объектам электросетевого хозяйства, котельным и многоквартирным домам составила в 2018 г. 4,2 \% - 30 контрактов (рисунок).

За последние годы в России активное развитие получил энергетический перфоманс-контрактинг на региональных рынках. Так, в 2018 г. энергетические перфоманс-контракты были заключены в 56 субъектах Российской Федерации, тогда как в 2017 г. - в 52, в 2016 г. - в 49. В ценовом сегменте менее 100 млн руб. в 2018 г. на первом месте находится Республика Саха (Якутия), где стоимость всех контрактов, заключенных в 2018 г., составила 428,8 млн руб. Суммарная стоимость 13 энергетических перфоманс-контрактов, заключенных в Свердловской области в 2018 г., составила 411,6 млн руб. В Новгородской области 49 контрактов были заключены на сумму 385,9 млн руб., что составило 6,7 \% общего объема рынка (табл. 2).

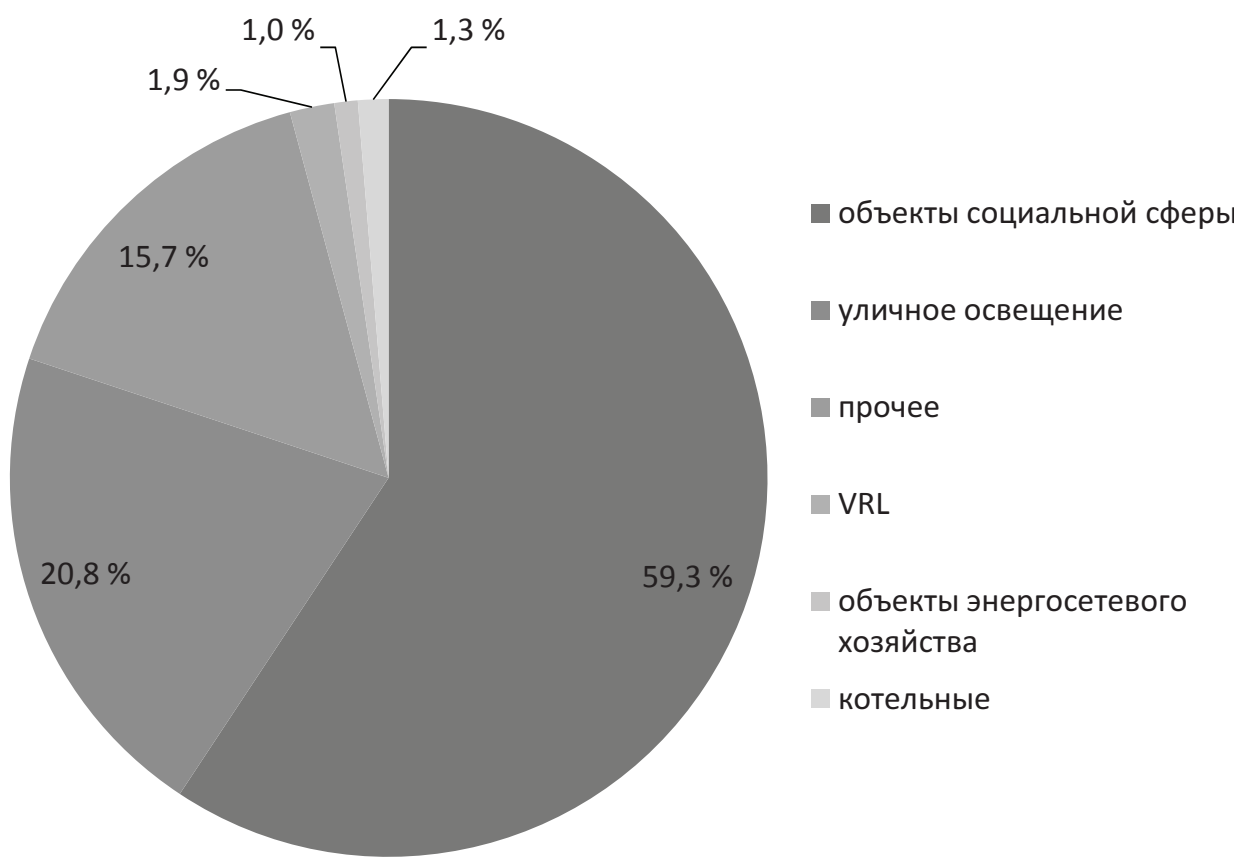

Рисунок. Распределение контрактов стоимостью менее 100 млн руб. в отраслевом разрезе за 2018 г. (составлено автором на основе статистических данных [14])

Т а бл и ц 2

Рынок энергетического перфоманс-контрактинга в региональном разрезе за 2018 г. (контракты стоимостью до 100 млн руб.) (составлено автором на основе статистических данных [14])

\begin{tabular}{|c|c|c|c|}
\hline Субъект РФ & Кол-во контрактов, ед. & $\begin{array}{c}\text { Стоимость контрактов, } \\
\text { млн руб. }\end{array}$ & $\begin{array}{c}\text { Удельный вес } \\
\text { по стоимости, \% }\end{array}$ \\
\hline Республика Саха (Якутия) & 21 & 428,8 & 7,4 \\
\hline Свердловская область & 13 & 411,6 & 7,1 \\
\hline Новгородская область & 49 & 385,9 & 6,7 \\
\hline Краснодарский край & 11 & 333,2 & 5,8 \\
\hline Ростовская область & 5 & 307,3 & 5,3 \\
\hline
\end{tabular}


Таким образом, проведенный анализ позволяет сделать вывод о том, что имеющийся потенциал по сокращению энергопотребления и повышению энергоэффективности даёт возможность использовать механизм перфоманс-контрактинга в России уже сегодня. Преимущества указанного механизма имели возможность оценить в предыдущие годы некоторые промышленные предприятия, а также отдельные территориальные общины и бытовые потребители.

\section{Заключение}

Сейчас в России сделаны только первые шаги для законодательного урегулирования возможностей применения перфоманс-контрактинга в бюджетной сфере, принимаются меры по совершенствованию тарифной политики, прорабатываются механизмы финансирования энергоэффективных проектов, в том числе по государственной и местной поддержке.

Среди причин, не способствующих массовому внедрению перфоманс-контрактинга, можно выделить следующие:

- несовершенная законодательная база;

- недостаточная осведомленность и техническая неподготовленность персонала организаций в части исполнения перфоманс-контрактов;

- отсутствие методологии реализации перфоманс-контрактов в неэнергетических сферах;

- слабая заинтересованность заказчиков в достижении экономии энергетических ресурсов.

Таким образом, успешное развитие перфоманс-контрактинга в энергетической сфере позволяет сделать обоснованный вывод о возможности его использования и в других неэнергетических отраслях, и в частности в процессе управления основными средствами промышленных предприятий. В основе предлагаемого подхода к использованию перфоманс-контрактинга в управлении основными фондами промышленных предприятий лежит идея о том, что исполнитель по такому контракту берёт на себя все риски внедрения новых объектов основных средств в реальных производствах. В этом случае компания будет осуществлять закупку и модернизацию объектов основных средств, привлекая необходимые для этого инвестиции и инвесторов, а заказчик, в случае получения успешных результатов, обязуется их внедрить, выкупив у компании. В рыночном отношении следует констатировать, что в условиях России предлагаемый механизм будет обладать огромным потенциалом.

В целях дальнейшего развития перфоманс-контрактинга в России можно предложить также ряд рекомендаций.

1. Создание необходимых законодательных рамочных условий:

- установление единых подходов к разработке технико-экономического обоснования энергоэффективных проектов;

- разработка механизмов стимулирования потребителей к внедрению энергоэффективных мероприятий;

- совершенствование процедур государственных закупок с учетом особенностей внедрения услуг энергосервиса.

2. Введение государственной поддержки и координации между участниками рынка с помощью таких мероприятий:

- создание новых и поддержка деятельности имеющихся фасилитаторов рынка (агентств, профильных ассоциаций, консультантов и т. п.) для содействия формированию спроса и предложения на перфоманс-контракты;

- разработка практических рекомендаций и пошаговых методик для потенциальных заказчиков по организации и воплощению энергоэффективных проектов с использованием механизмов перфоманс-контрактинга;

- создание системы повышения квалификации специалистов в области разработки и реализации перфоманс-контрактов (тренинги, учебные программы, методические рекомендации и т. п.);

- начало программы обучения по вопросам финансовых механизмов, которые применяются в перфоманс-контрактинге для сотрудников местных финансовых учреждений (например, банки, револьверные фонды).

Таким образом, рынок перфоманс-контрактинга выступает реальным инструментом повышения эффективности управления основными фондами промышленных предприятий не только в части энергетического оборудования, но и в части других объектов основных средств, в том числе и их пассивной части. В связи с этим необходимо продолжить работу по внедрению механизмов стимулирования промышленных предприятий в области применения перфоманс-контрактов для финансирования проектов и мероприятий по обновлению и модернизации основных фондов, а также повышению их энергоэффективности, что позволит осуществлять привлечение новых инвестиций в энергосбе- 
режение и обеспечит возврат инвестированных средств за счет экономии финансовых ресурсов.

В дальнейших исследованиях необходимо определить региональные особенности рынка перфоманс-контрактинга в России, а также принципы его функционирования и усовершенствования методической базы для проведения экономической оценки эффективности его функционирования.

\section{Библиографический список}

1. Бозиева Ю. Г., Муртазова М. А. Преимущества и скрытый эффект перфоманс-контракта // NovaInfo.Ru. 2016. T. 1, № 57. C. 409-412.

2. Бозиева Ю. Г., Чапаев А. Б. Способы реализации энергосбережения по средствам применения перфоманс-контрактов // Актуальные проблемы и приоритетные инновационные технологии развития АПК региона. Материалы Всероссийской научно-практической конференции преподавателей, аспирантов, магистрантов и студентов. 2015. C. 250-252.

3. Бурчакова A. А. Энергосервис в России: вопросы методологии анализа и факторы развития // Интернет-журнал Науковедение. 2016. Т. 8, № 2 (33). C. 18.

4. Грачев Н. К. Энергосервисный договор как развивающийся институт в российском праве // Вопросы российского и международного права. 2018. T. 8, № 5A. С. 149-156.

5. Гуськова Н. Д., Ульянкин О. В. Преимущества и скрытый эффект перфоманс-контракта // Проблемы экономики и менеджмента. 2015. № 3 (43). С. $16-19$.

6. Измайлов М. К., Кобзев В. В. Подход к формированию перфоманс-контрактов управления основными средствами промышленного предприятия // Научно-технические ведомости СПбГПУ. Экономические науки. 2018. Т. 11, № 5. С. 111-118.

7. Кирюдчева А. Е., Немова Д. В. Энергосервисные контракты в России и в Европейском союзе // Строительство уникальных зданий и сооружений. 2017. № 10 (61). С. 7-21.

8. Левицкая A. В. Исследование альтернативных вариантов финансирования проектов по повышению энергетической эффективности // Экономика: реалии времени. 2015. № 4 (20). C. 256-260.

9. Лымарева Т. П. Развитие энергосервисной деятельности в строительстве и эксплуатации жилья // Экономика строительства. 2017. № 3 (45). C. $13-23$.

10. Мукумов Р. Э., Адрианов В. В., Захаров А. П. Развитие рынка энергосервиса в России. Состояние

\section{Источник финансирования}

Источником финансирования процесса исследования являются средства автора.

\section{Конфликт интересов}

Автор декларирует отсутствие явных и потенциальных конфликтов интересов, связанных с публикацией настоящей статьи.

и перспективы // Энергосовет. 2015. № 6 (25). C. 26-30

11. Назарова Л. Е. Анализ опыта применения энергосервисных контрактов в России // Дайджест-финансы. 2017. Т. 22, № 1 (241). С. 50-61.

12. Плотников А. Н. Решение проблем внедрения инновационного энергоэффективного оборудования с помощью перфоманс-контрактов // Актуальные проблемы экономики и менеджмента. 2018. № 1 (17). С. 79-84.

13. Родионова И. А., Мареева М. А. Энергосервис как инструмент повышения энергоэффективности: теоретические аспекты и практика применения // Экономика и предпринимательство. 2018. № 1 (90). С. 978-984.

14. Российский рынок энергосервиса, 2018. Исследование Ассоциации энергосервисных компаний. М. : АЭК, 2019. 14 с.

15. Седаш Т., Каменева Е., Егорова Д. Зарубежный опыт энергосервиса в ЖКХ : перспективы развития в России // РИСК: Ресурсы, Информация, Снабжение, Конкуренция. 2016. № 1. С. 130-133.

16. Сотник И. Н., Кулик Л. А. Эффективный энергоменеджмент: теоретические основы финансовой деятельности энергосервисных компаний // Маркетинг и менеджмент инноваций. 2015. № 3. C. 212-225.

17. Тупикина A. A. Возможные участники энергосервисного контракта и схемы их взаимодействия // Экономика и гуманитарные исследования: проблемы, тенденции, достижения : сб. материалов II Междунар. науч.-практ. конф. 2017. С. 123-129.

18. Ульянкин О. В. Совершенствование алгоритма реализации перфоманс-контракта // Экономика и предпринимательство. 2015. № 4-1 (57). С. 962-965.

19. Хуснутдинова О. Б. Энергосервисный контракт как инструмент привлечения инвестиций в электросетевой комплекс России // Перспективы развития науки и образования : сб. науч. трудов по материалам Междунар. науч.-практ. конф. : в 8 ч. АР-Консалт. 2015. С. 70-74.

20. Чапаев А. Б. Перфоманс-контракт : опыт внедрения // NovaInfo.Ru. 2016. T. 1, № 55. C. 72-76. 
Измайлов Максим Кириллович, старший преподаватель высшей школы управления и бизнеса, Санкт-Петербургский политехнический университет Петра Великого (СПбПУ), Санкт-Петербург, Российская Федерация

E-mail: izmajlov_mk@spbstu.ru

ORCID ID: 0000-0002-3147-9603

Поступила в редакцию 14.03.2020

Подписана в печать 14.04.2020 


\title{
Analysis of the experience of performance contracting development in Russia
}

\author{
M. K. Izmaylov ${ }^{1 凶}$ \\ ${ }^{1}$ Peter the Great St. Petersburg Polytechnic University (SPbPU), Graduate School of Business \\ and Management, Polytechnicheskaya str., 29, 195251, St. Petersburg, Russian Federation
}

Cite as: Izmaylov, M. K. (2020) Analysis of the experience of performance contracting development in Russia. Proceedings of Voronezh State University. Series: Economics and Management. 4, 65-73. (In Russ., abstract in Eng.). DOI: 10.17308/econ.2020.4/3194

\begin{abstract}
Importance. To date, performance contracts in terms of modernization and management of fixed assets are practically not used in the economy of the Russian Federation and, in particular, at the level of industrial enterprises. The entire experience of developing performance Contracting in Russia is directly related to energy service contracts. At the same time, the existing potential to reduce energy consumption and increase energy efficiency makes it possible to use the performance Contracting mechanism in Russia today. The successful development of performance Contracting in the energy sector allows us to make a reasonable conclusion about the possibility of its use in other non-energy sectors, and in particular in the process of managing the fixed assets of industrial enterprises. The proposed approach to the use of performance Contracting in the management of fixed assets of industrial enterprises is based on the idea that the contractor under such a contract assumes all the risks of introducing new fixed assets in real production. Objectives is to analyze the problems of performance Contracting development in Russia and develop recommendations for its development.

Methods. In the process of achieving these goals, the following methods of scientific knowledge were used: dialectical; analysis and synthesis. The research is based on the study of current scientific and periodical economic literature.

Results. A brief history of the formation and development of energy service contracts is given. The main statistical data that characterize the development of the performance Contracting market in Russia at the current stage are reflected.

Conclusions. Based on the conducted research, the necessity of using performance Contracting in the management of fixed assets of industrial enterprises is justified. The final part of the article presents the main reasons that hinder the mass development of performance Contracting in Russia,as well as some recommendations for its development. The conclusion is based on the need to continue work on the introduction of incentive mechanisms for industrial enterprises in the field of performance contracts for financing projects and activities to update and modernize basic funds, as well as to improve their energy efficiency, which will allow attracting new investments in energy conservation and ensure the return of invested funds by saving financial resources.
\end{abstract}

Key words: performance Contracting, energy service contracts, energy efficiency, performance contract, fixed assets.

\section{Source of Financing}

The source of funding for the research process is the author's funds.

\section{References}

1. Bozieva Y. G., M. A. Murtazova (2016) Benefits and the hidden effect of performance-contract. NovaInfo.Ru. 1 (57), 409-412. (In Russian).

2. Bozieva Yu. G., Chapayev, A. B. (2015) Methods of implementing energy saving by means of the use

\section{Conflict of Interest}

The author declare that there are no obvious or potential conflicts of interest associated with the publication of this article.

of performance contracts. Actual problems of priority and innovative technologies of development of the agroindustrial complex of the region. Materials of the all-Russian scientific and practical conference of teachers, postgraduates, undergraduates and students, 250252. (In Russian). 
3. Burchakova A. A. (2016) Energoservice in Russia: issues of analysis methodology and development factors. The online journal of the sociology of Science. 2 (33), 18-19 (In Russian).

4. Grachev N. K. (2018) Energy Service agreement as a developing institution in Russian law. Questions of Russian and international law. 5A, 149-156. (In Russian).

5. Guskova N. D., Ulyankin O. V. (2015) Advantages and hidden effect of the performance contract. Problems of Economics and management. 3 (43), 16-19. (In Russian).

6. Izmailov M. K., Kobzev V. V. (2018) Approach to the formation of performance contracts for the management of fixed assets of industrial enterprises, Scientific and technical statements of SPbGPU. Economics. 5, 111-118 (In Russian).

7. Kiryudcheva A. E., Nemova D. V. (2017) Energy Service contracts in Russia and the European Union. Construction of unique buildings and structures, 10 (61), 7-21. (In Russian).

8. Levitskaya A.V. (2015) Research of alternative options for financing projects to improve energy efficiency. Economy: the realities of time. 4 (20), 256-260. (In Russian).

9. Lymareva T. P. (2017) Development of energy service activities in housing construction and operation. Construction economics. 3 (45), 13-23. (In Russian).

10.Mukumov R. E., Adrianov V. V., Zakharov A. P. (2015) Development of the energy service market in Russia. Status and prospects. Power supply. 6 (25), 2630 (In Russian).

11. Nazarova L. E. (2017) Analysis of the experience of using energy service contracts in Russia. Digest-Finance. 1 (241), 50-61. (In Russian).

12. Plotnikov A. N. (2018) Solving problems of implementing innovative energy-efficient equipment using performance contracts. Actual problems of Economics and management. 1 (17), 79-84. (In Russian).

13. Rodionova I. A., Mareeva M. A. (2018) Energoservice as a tool for improving energy efficiency: theoretical aspects and application practice. Economics and entrepreneurship. 1 (90), 978-984. (In Russian).

14.Russian energy service market, 2018. Research Of the Association of energy service companies, Moscow, AEK Publishing house, 2019. (In Russian).

15. Sedash T., Kameneva E., Egorova D. (2016) Foreign experience of power supply in housing and utilities: development prospects in Russia. RISK: Resources, Information, Supply, Competition. 1, 130-133. (In Russian).

16. Sotnik I. N., Kulik L. A. (2015) Effective energy management: theoretical foundations of financial activity of energy service companies. Marketing and innovation management. 3, 212-225. (In Russian).

17. Tupikina A. A. (2017) Possible participants of the energy service contract and their interaction schemes. Economics and Humanities research: problems, trends, achievements. collection of materials of the II International scientific and practical conference. 123-129. (In Russian).

18. Ulyankin O. V. (2015) Improving the algorithm for implementing a performance contract. Economics and entrepreneurship. 4-1 (57), 962-965. (In Russian).

19. Khusnutdinova O. B. (2015) Energy Service contract as a tool for attracting investment in the Russian electric grid complex. Prospects for the development of science and education. Collection of scientific papers on the materials of the International scientific and practical conference: in 8 parts. AR-consult. $70-74$. (In Russian).

20. Chapaev A. B. (2016) Performance contract: implementation experience. NovaInfo.Ru. 55, 72-76. (In Russian).

Izmaylov Maxim Kirillovich, senior lecturer, Graduate School of Business and Management, Peter the Great St. Petersburg Polytechnic University (SPbPU), St. Petersburg, Russian Federation

E-mail:izmajlov_mk@spbstu.ru

ORCID ID: 0000-0002-3147-9603

Received 14.03.2020

Accepted 14.04.2020 